\section{A Modified Nutrient Film Technique System Offers a More Uniform Nutrient Supply to Plants}

\author{
Alejandro R. Puerta, Suguru Sato ${ }^{1,2}$, Yutaka Shinohara, \\ and Toru Maruo
}

AdDITIONAL INDEX wORDs. lettuce, Lactuca sativa, hydroponics, plant quality, low nitrate content, dissolved oxygen, nutrient film technique

Summary. In nutrient film technique (NFT) vegetable production, the use of lowconcentration nutrient solutions might lead to a nutrient concentration gradient along the bed, which can translate into nonuniform plant growth. The authors modified a conventional NFT system (cNFT) and propose a modified NFT (mNFT) that enables the production of lettuce (Lactuca sativa) plants of uniform fresh weight along elongated cultural beds. Two experiments were carried out to compare the systems when long cultural beds are used $(18 \mathrm{~m})$ in terms of uniformity of plant and nutrient solution characteristics. The results indicated that fresh weight of plants in cNFT decreased as the distance from the nutrient inlet increased, whereas no such trend was observed in mNFT. Leaf nitrate concentration in mNFT was uniform, whereas it was higher near the outlet of cNFT. Ascorbic acid concentration was also uniform in mNFT, but it was found to be lower near the outlet of cNFT. During Expt. 2, the oxygen content along the bed decreased from inlet to outlet in cNFT; however, in mNFT, it remained relatively constant at all sampling positions. Regarding the concentration of the nutrient solution along beds, no significant differences were found between inlet and outlet in both systems. It is suggested that the lower concentration of oxygen found at the outlet of cNFT might have reduced nutrient uptake, thus attenuating the difference in concentration between inlet and outlet. The temperatures of the nutrient solution along mNFT during Expt. 2 tended to be slightly lower than those of cNFT. However, temperatures were still too high and plant growth was negatively affected. The results of this study demonstrate that plants of uniform size and quality can be achieved in long cultural beds (up to $18 \mathrm{~m}$ long) supplied with a low-concentration fertilizer solution by using the proposed mNFT.

$\mathrm{N}$ utrient film technique (NFT) is the most widespread method of growing plants in a continuously recirculating nutrient solution system (Saavas, 2002). Recirculation of nutrient solution has two beneficial aspects: 1) it reduces the emission of effluents and 2) it increases water and nutrient use efficiencies. Recent environmental regulations to conserve groundwater and to minimize water and fertilizer consumption (Saavas, 2001) have highlighted

\footnotetext{
Faculty of Horticulture, Chiba University, 648 Matsudo, Matsudo City, Chiba 271-8510, Japan

Funded by the Ministry of Education, Culture, Sports, Science and Technology of Japan (MEXT).

We thank Nobusato Majima for his help with the nutrients determinations and Takeshi Okano for his advice and untiring assistance in the construction of the hydroponic systems.

${ }^{1}$ Corresponding author. E-mail: suguru.sato@fas. usda.gov

${ }^{2}$ Current address: USDA-FAS, Embassy of the United States, 1-10-5, Akasaka, Minato-ku, Tokyo, 107-8420,
} Japan. the importance of nutrient solution recycling and encouraged the shift from open to closed hydroponic systems.

Closed recycling systems have some limitations. Absorption rates of the nutrients tend to vary, and these variations result in an imbalance between the ion concentrations (Schröder and Lieth, 2002). Therefore, the solution has to be eventually renewed. However, the disposal of diluted solutions is not likely to damage the environments. Lettuce plants grown in low-nutrient concentration accumulate lower amounts of ions, especially nitrates in leaves (Andersen and Nielsen, 1992; Maršić and Osvald, 2002; Van Der Boon et al., 1990). However, commercial intensive cropping generally requires maintaining a relatively high concentration of nutrient solution (Maruo et al., 2001; Raviv, 1998).

Maintaining high levels of ions has various disadvantages (Pardossi et al., 1995), and using a lower nutrient concentration would mitigate them. However in a conventional NFT (cNFT) system, it has been observed that significant differences in the concentration of nutrients and oxygen near the inlet and outlet of the channel occur when long beds are used (Gislerød and Adams, 1983; Gislerød and Kempton, 1983; Jackson, 1980; Jackson et al., 1984; Winsor and Massey, 1978). To avoid weakening of nutrient solution concentrations near outlets, nutrient channels no longer than $9 \mathrm{~m}$ are recommended (Jones, 1997). Shorter beds may not be a reasonable solution for many growers because it would significantly increase capital expenditures for pumps and tanks in production. To overcome these problems, we propose a modified NFT (mNFT) system that can supply low nutrient concentrations uniformly along long cultural beds (Maruo et al., 2001). The modifications consist of the inclusion of a second "sideward" (transversal, 3\%) slope and the addition of an irrigation hose along the upper side of the inclined bed. As a result of these modifications, a new flow of nutrient solution is established in which the solution enters the bed through the hose and flows diagonally from the upper lateral side of the bed to the lower lateral side, where it is collected by a drainage

\begin{tabular}{llll}
\hline $\begin{array}{l}\text { Units } \\
\text { To convert U.S. to SI, } \\
\text { multiply by }\end{array}$ & U.S. unit & SI unit & $\begin{array}{l}\text { To convert SI to U.S., } \\
\text { multiply by }\end{array}$ \\
\hline 0.3048 & $\mathrm{ft}$ & $\mathrm{m}$ & 3.2808 \\
3.7854 & gal & $\mathrm{L}$ & 0.2642 \\
2.5400 & inch(es) & $\mathrm{cm}$ & 0.3937 \\
25.4000 & inch $(\mathrm{es})$ & $\mathrm{mm}$ & 0.0394 \\
1 & mmho/cm & $\mathrm{dS} \cdot \mathrm{m}^{-1}$ & 1 \\
28.3495 & $\mathrm{oz}$ & $\mathrm{G}$ & 0.0353 \\
1 & $\mathrm{ppm}$ & $\mathrm{mg} \cdot \mathrm{L}^{-1}$ & 1 \\
1 & $\mathrm{ppm}$ & $\mu \mathrm{L} \cdot \mathrm{L}^{-1}$ & 1 \\
$\left({ }^{\circ} \mathrm{F}-32\right) \div 1.8$ & ${ }^{\circ} \mathrm{F}$ & ${ }^{\circ} \mathrm{C}$ & $\left(1.8 \times{ }^{\circ} \mathrm{C}\right)+32$
\end{tabular}


channel $(5 \mathrm{~cm}$ wide) and conducted to the catchment tank. The distance covered by the solution in its way through the bed is considerably shorter than the whole length of the channel. Thus, a uniform distribution of the nutrient solution is expected. Therefore, the objective of this study was to compare a cNFT and an mNFT to determine whether the modifications truly represent an improvement.

\section{Materials and methods}

General Procedures. Lettuce seeds of cultivar L-2 (Mikado Seed Co., Chiba, Japan) were sown on 20 Apr. 2005 (Expt. 1) in foam rubber cubes $(24 \times 24 \times 29 \mathrm{~mm})$ and placed in a tray $(288 \times 600 \times 29 \mathrm{~mm})$. Two liters of a half-strength modified Hoagland solution \{electric conductivity $(\mathrm{EC})=1.2 \mathrm{dS} \cdot \mathrm{m}^{-1}, 0.472$ $\mathrm{mg} \cdot \mathrm{L}^{-1}$ calcium nitrate tetrahydrate $\left[\mathrm{Ca}\left(\mathrm{NO}_{3}\right)_{2} \cdot 4 \mathrm{H}_{2} \mathrm{O}\right], 0.404 \mathrm{mg} \cdot \mathrm{L}^{-1}$ potassium nitrate $\left(\mathrm{KNO}_{3}\right), 0.077$ $\mathrm{mg} \cdot \mathrm{L}^{-1}$ ammonium dihydrogen phosphate $\left(\mathrm{NH}_{4} \mathrm{H}_{2} \mathrm{PO}_{4}\right), 0.246 \mathrm{mg} \cdot \mathrm{L}^{-1}$ magnesium sulfate heptahydrate $\left(\mathrm{MgSO}_{4} \cdot 7 \mathrm{H}_{2} \mathrm{O}\right), \quad 23.576 \mathrm{mg} \cdot \mathrm{L}^{-1}$ Fe-EDTA $\left(\mathrm{C}_{10} \mathrm{H}_{12} \mathrm{Fe}_{1} \mathrm{~N}_{2} \mathrm{O}_{8}\right), 2.85$ $\mathrm{mg} \cdot \mathrm{L}^{-1}$ boric acid $\left(\mathrm{H}_{3} \mathrm{BO}_{3}\right), 2.109$ $\mathrm{mg} \cdot \mathrm{L}^{-1}$ magnesium sulfate tetrahydrate $\left(\mathrm{MnSO}_{4} \cdot 4 \mathrm{H}_{2} \mathrm{O}\right), 0.222 \mathrm{mg} \cdot \mathrm{L}^{-1}$ zinc sulfate heptahydrate $(\mathrm{Zn}$ $\left.\mathrm{SO}_{4} \cdot 7 \mathrm{H}_{2} \mathrm{O}\right), 0.078 \mathrm{mg} \cdot \mathrm{L}^{-1}$ copper sulfate pentahydrate $\left(\mathrm{CuSO}_{4} \cdot 5 \mathrm{H}_{2} \mathrm{O}\right)$, and $0.022 \mathrm{mg} \cdot \mathrm{L}^{-1}$ disodium molybdenum tetraoxide $\left(\mathrm{Na}_{2} \mathrm{MoO}_{4} \cdot 2 \mathrm{H}_{2} \mathrm{O}\right)$ \} were added, and absorbent paper was put on top of the foam rubber cubes. The tray was wrapped in a black plastic bag and was placed in a growth chamber. After $3 \mathrm{~d}$, the black plastic bag and the absorbent paper were removed and the tray was kept in the chamber for another $5 \mathrm{~d}$. During this period, a half strength of modified Hoagland solution was added as needed. The environmental conditions in the growth chamber were set as follows: $25 / 18{ }^{\circ} \mathrm{C}$ light/dark temperatures, $250 \mu \mathrm{mol} \cdot \mathrm{m}^{-2} \cdot \mathrm{s}^{-1}$ photosynthetic photon flux, 12-h photoperiod, $1000 \mathrm{ppm}$, and $\mathrm{CO}_{2}$. Eight days after sowing, the seedlings together with the foam rubber cubes were transplanted into the two NFT systems, which were constructed in a greenhouse located in the experimental field of the Faculty of Horticulture, Chiba University (Matsudo City, Chiba, Japan; lat. $35^{\circ} 46^{\prime} 48^{\prime \prime} \mathrm{N}$, long. $\left.139^{\circ} 55^{\prime} 48^{\prime \prime} \mathrm{E}\right)$.
A second experiment was performed in the same way as the first one. In this case, seeds were sown on 8 July 2005 . As mentioned later, in this experiment different flow rates were used.

Nutrient film technique SYSTEMS. The cNFT system consisted of an 18 -m-long nutrient channel with a $1 \%$ slope (longitudinal), a catchment tank, and a pump (C-P60J; Hitachi, Tokyo, Japan). The mNFT system differed from the cNFT in two aspects: a second sideward slope (transversal, 3\%) and an irrigation hose (Evaflow A; Mitsui Chemicals, Tokyo) placed at the upper lateral side of the secondary slope and run along the bed ( $18 \mathrm{~m}$; Fig. 1A, B). A drainage channel $(5 \mathrm{~cm}$ wide) was located next to the lower lateral side of the bed to collect the solution that was coming diagonally from the irrigation hose and to conduct it to the catchment tank (Fig. 1C). The same catchment tank was used for both systems to ensure that the composition of the nutrient solution was identical. During Expt. 1, the flow rate of the nutrient solution was set at
1.5 and $3.8 \mathrm{~L} \cdot \mathrm{min}^{-1}$ for the $\mathrm{CNFT}$ and mNFT respectively. The reason for the difference in flow rate between both treatments resides in the fact that although a flow rate between 1 and $2 \mathrm{~L} \cdot \mathrm{min}^{-1}$ is widely recommended for NFTs (Cooper, 1979; Jones, 1997), the mNFT requires a higher flow rate because the actual inlet of the system is the total length of the channel (i.e., $18 \mathrm{~m}$ ). In Expt. 2, the flow rate of the mNFT was increased to $7.5 \mathrm{~L} \cdot \mathrm{min}^{-1}$ by using a different pump (25SCD; EBARA Corp., Rock Hill, S.C.), with the purpose of determining whether better performance can be achieved.

In both systems, a 36-cm-wide capillary mat was placed at the base of each channel. Styrofoam boards $(90 \times$ $180 \mathrm{~cm}, 10$ boards every two attached channels) with holes $15 \mathrm{~cm}$ apart were placed on top of the channels to provide mechanical support to the plants. Each bed consisted of two lines of holes with room for 240 plants.

The catchment tank was initially filled with $150 \mathrm{~L}$ of a half-strength modified Hoagland solution and the

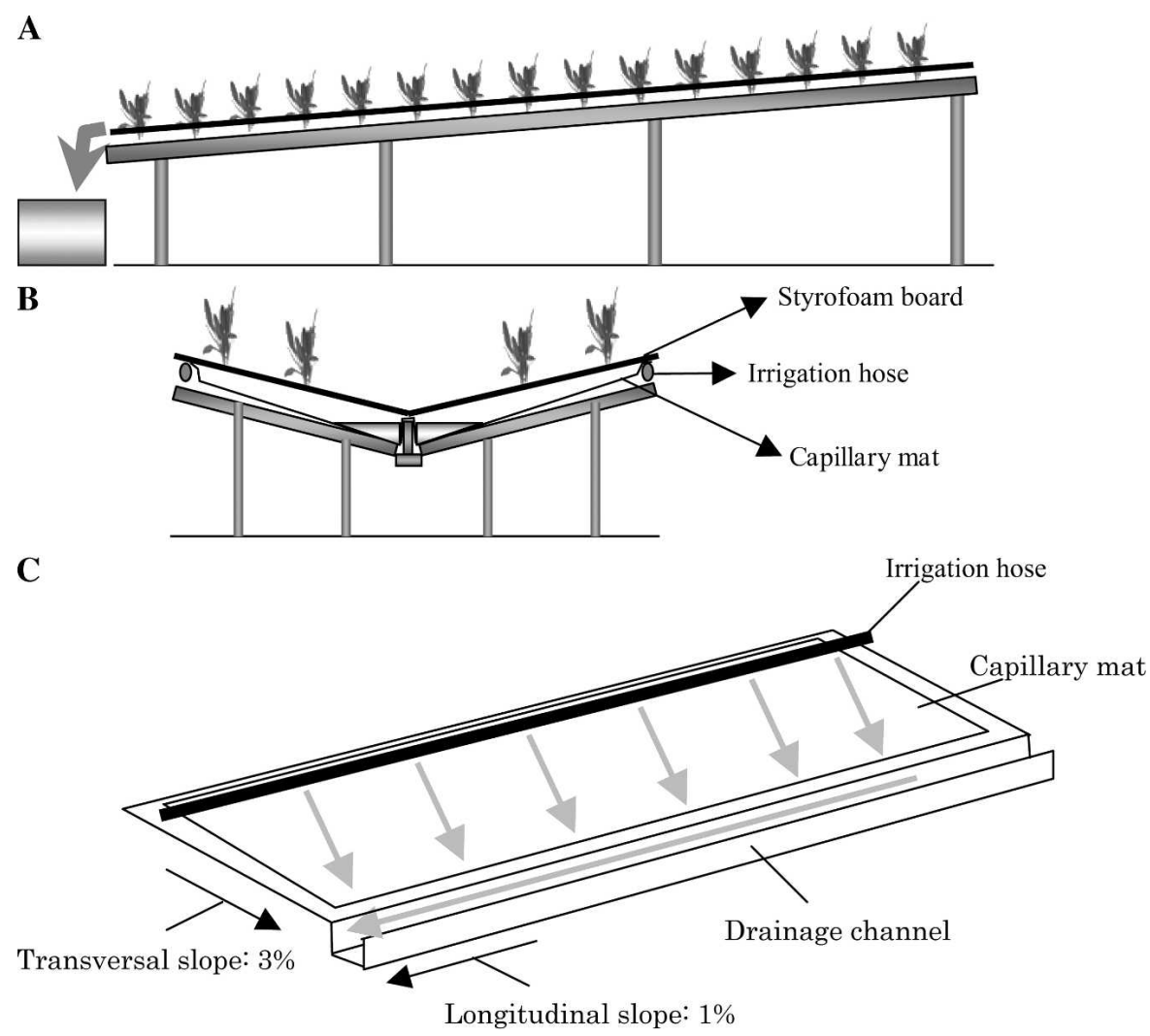

Fig. 1. Representation of the modified nutrient film technique system showing its basic components. (A) lateral view. (B) Frontal view. (C) Diagram depicting the flow of the nutrient solution. 
volume was kept constant by using a level sensor (OLV-2A, Nohken, Osaka, Japan; Fig. 2). When activated, the sensor sent a signal to a pinch valve (PK-0305-NC; Takasago Electric, Nagoya, Japan), which opened, allowing the addition of water. The volume of water added was measured by a flowmeter (FHK Digmesa AG, Ipsach, Germany) and a counter (H7GP; Omron Co., Kyoto, Japan). Ion concentrations were maintained at an EC target value of $1.2 \mathrm{dS} \cdot \mathrm{m}^{-1}$ with an EC controller (HI933700; Hanna Instruments, Woonsocket, R.I.), which sent a signal to a pinch valve (PK-0305-NC), which opened, allowing the addition of concentrated modified Hoagland solution $(10 \times)$. The volume of stock solution supplied was determined by using flow meters and counters as described earlier. The actual EC value was $1.2 \pm 0.2 \mathrm{dS} \cdot \mathrm{m}^{-1}$ throughout both experiments. The $\mathrm{pH}$ of the nutrient solution was kept between 5.5 and 6.5 .

Harvest and analysis. At harvest, the beds were divided into 10 sections of $1.62 \mathrm{~m}^{2}$ and samples were taken separately from every section to determine fresh weight (FW). Dry weight, nitrate content, ascorbic acid of the solution were determined from samples taken from three locations in the beds: inlet $(0-1.8 \mathrm{~m}$ from inlet), middle (8.1-9.9 m), and outlet (16.2-18 m). Dry weight was measured after the samples were ovendried for $5 \mathrm{~d}$ at $60{ }^{\circ} \mathrm{C}$. Nitrate concentration as well as ascorbic acid content in fresh samples were determined reflectometrically (RQflex plus; Merck, Darmstadt, Germany). The nutrient solution concentrations of content, and nutrient concentration

nitrate $\left(\mathrm{NO}_{3}^{-}\right)$and phosphate $\left(\mathrm{PO}_{4}{ }^{3-}\right)$ were determined by colorimetric reactions measured on a spectrometer (U-2000; Hitachi). Concentrations of potassium $\left(\mathrm{K}^{+}\right)$, calcium $\left(\mathrm{Ca}^{2+}\right)$, and magnesium $\left(\mathrm{Mg}^{2+}\right)$ were determined by flame ionization atomic absorption spectrophotometry on a spectrometer (Z-6100; Hitachi). Nutrient solution was sampled every $6 \mathrm{~d}$ from the catchment tank. The chlorophyll content of leaves was determined using a portable chlorophyll meter (SPAD-502; Minolta Co., Tokyo).

In Expt. 2, dissolved oxygen and nutrient solution temperature were also measured (F102; Iijima Electronics Corp., Tokyo) at the inlet, middle, and outlet of the beds during and after the cultivation period (consecutive $3 \mathrm{~d}$ right after the harvest). Temperature in the greenhouse was monitored by a temperature data logger (TR-71U; T\&D Corp., Tokyo).

Analysis of variance, Tukey's test (when needed), and linear regression were performed by using SigmaStat (version 2.03; Access Softek, Berkeley, Calif.) statistical software. The two experiments were analyzed separately.

\section{Results and discussion}

Average plant FW in each section from Expt. 1 and 2 is presented in Fig. 3. Although yields of both systems were comparable, the distribution of plant FW along the beds was clearly affected by the treatments. Although the mNFT system produced plants with similar FW in all sampling sites regardless of the season, significant differences $(P<0.001)$ were found between the plants grown in cNFT in both experiments. Fresh weights tended to decrease as the distance

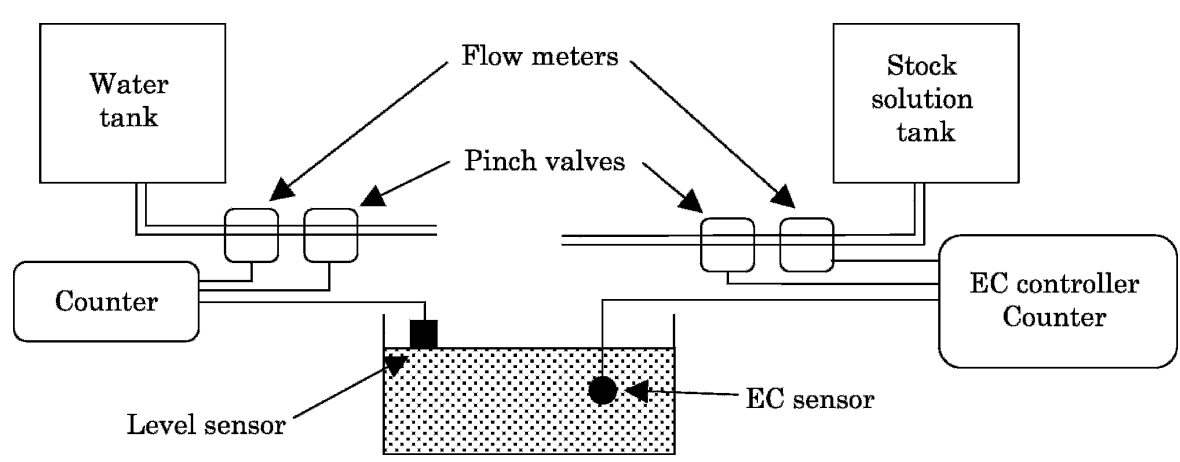

Fig. 2. Diagram of the nutrient film technique system used to control water and stock solution supply to the catchment tank during the experiments. EC, electrical conductivity. from the inlet increased, as shown by the linear regressions. However, the divergence of the average weight in each section from the general average for cNFT was less in Expt. 2 (106.9\% to $79.9 \%)$ than in Expt. 1 ( $127.1 \%$ to $68.2 \%$ ). The divergence in mNFT was even narrower $(105.0 \%$ to $94.7 \%$ and $102.7 \%$ to $97.9 \%$ respectively). Similarly, within each section the $\mathrm{SE}$ was considerably larger in cNFT than in mNFT, indicating a greater variability in plant $\mathrm{FW}$ at harvest.

Yield differences observed between the experiments could have been incited by temperature differences between Expt. 1 and Expt. 2, a shorter growing cycle $(4 \mathrm{~d}$ shorter in Expt. 2 to avoid stem elongation), and the need to use shade $(50 \%)$ during sunny days in the last weeks of Expt. 2. It has been reported that the optimal growth temperature for lettuce is between 13 and $18{ }^{\circ} \mathrm{C}$ (Halfacre and Barden, 1979; Thompson and Kelly, 1957); however, the ambient temperature in the greenhouse of our experiment often exceeded $30{ }^{\circ} \mathrm{C}$ during the latter half of Expt. 2. Generally, plants of $80 \mathrm{~g}$ FW or more are marketed as "large" in the Japanese market. Similarly, plants between 60 and $80 \mathrm{~g} \mathrm{FW}$ are marketed as "medium." Yields obtained during Expt. 1 were, in almost all sections, well above 100 $\mathrm{g} /$ plant, which is excessive considering that lighter plants $(65-70 \mathrm{~g})$ are preferred in this market. A slightly shorter growing cycle would prevent this. However, if the average FW in the plants near the inlet in cNFT had been $\approx 100 \mathrm{~g}$, those near the outlet would only have reached the $60 \mathrm{~g}$ needed to be marketed as "medium." Conversely, in mNFT, the shortening of the cropping period per se would have resulted in plants of uniform size that would have fallen into the same commercial category.

No consistent trends or differences were found in nitrate concentration of lettuce leaves either between NFT systems or sampling locations (Fig. 4). In Expt. 1, the nitrate concentration of the plants at the outlet of cNFT was found to be significantly higher $(P=0.032)$ than that of the plants located at the inlet. The nitrate concentration of plants in mNFT was significantly lower $(P=$ 0.041) than that in cNFT in Expt. 2. 
Expt. 1

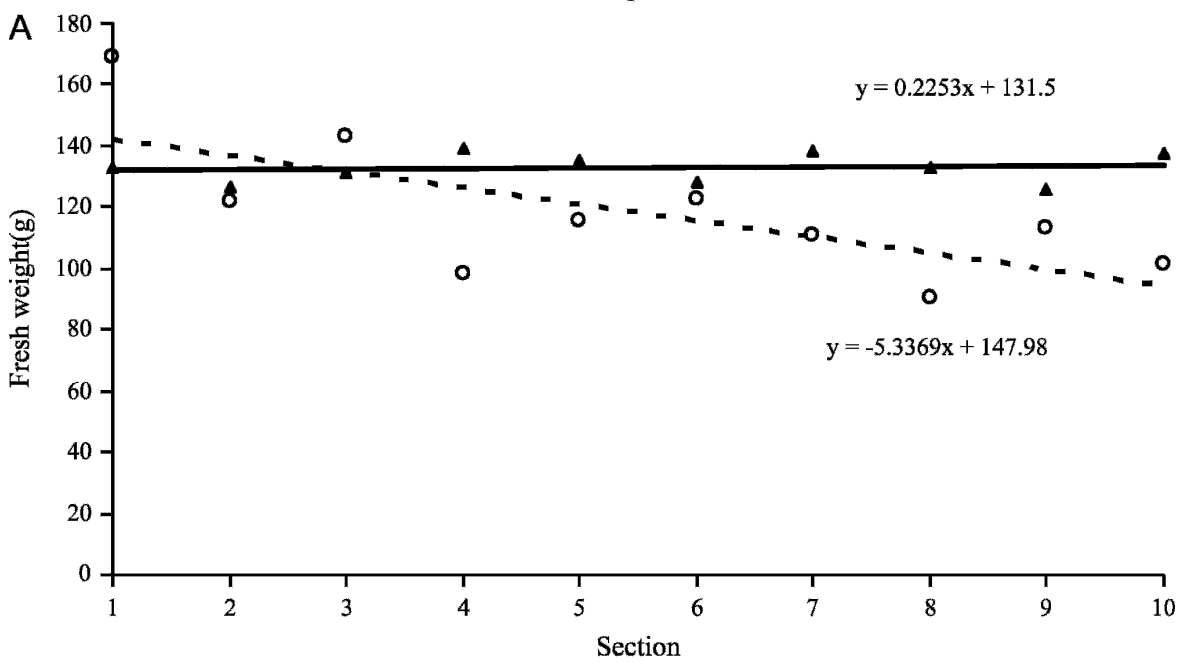

○ cNFT \& mNFT - . - . Linear (cNFT) Linear(mNFT)

Expt. 2

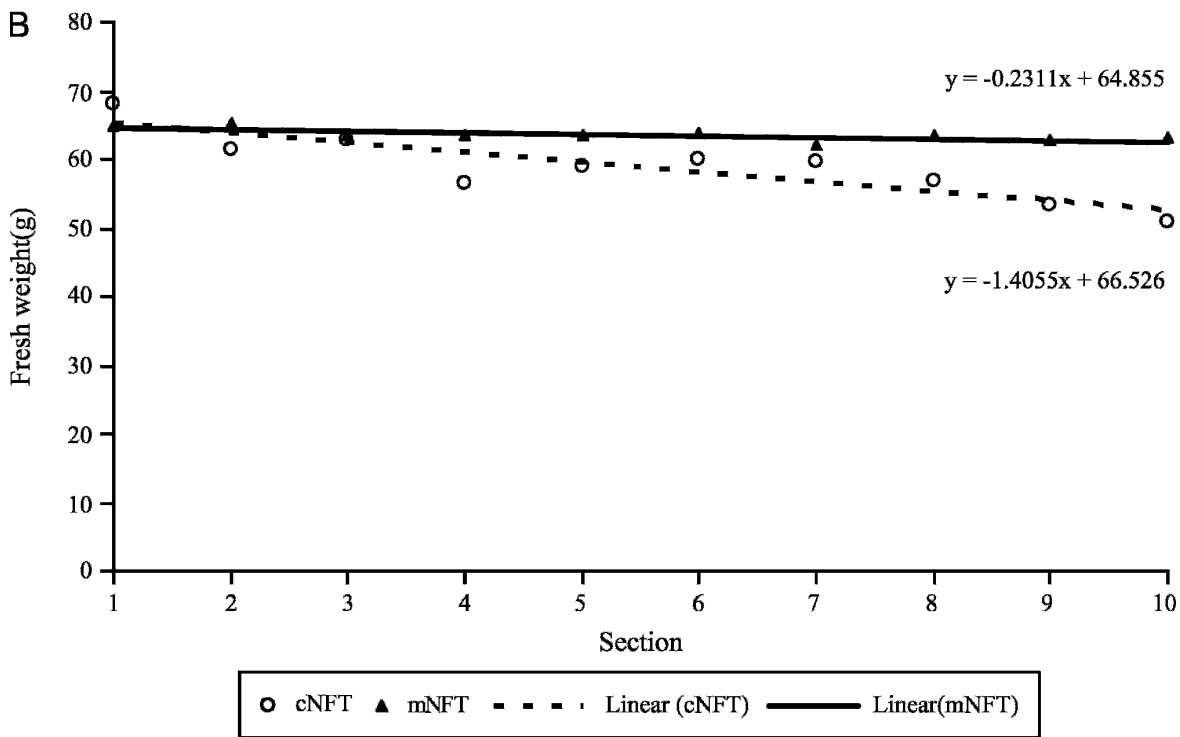

Fig. 3. (A, B) Fresh weight of lettuce plants produced in a conventional nutrient film technique (cNFT) and a modified nutrient film technique (mNFT) system during Expt. 1 (A) and Expt. 2 (B) according to the position in 18-m-long (59.1-ft) beds. Each value was averaged from 15 observations. Regression equations were $y=$ $-5.3369 \mathrm{x}+147.98\left(r^{2}=0.4952\right)$ for Expt. $1 \mathrm{cNFT}, \mathrm{y}=0.2253 \mathrm{x}+131.5\left(r^{2}=\right.$ $0.0188)$ for Expt. $1 \mathrm{mNFT}, \mathrm{y}=-1.4055 \mathrm{x}+66.526\left(r^{2}=0.7617\right)$ for Expt. $2 \mathrm{cNFT}$, and $\mathrm{y}=-0.2311 \mathrm{x}+64.855\left(r^{2}=0.5767\right)$ for Expt. $2 \mathrm{mNFT}$. $1 \mathrm{~g}=0.0353 \mathrm{oz}$.

Considering the maximum levels of nitrate for lettuce established by the Commission of the European Communities (Official Journal of the European Communities, 2002), the plants harvested in the outlet and middle of the bed of cNFT during Expt. I could be marketed, whereas the plants from the outlet would be rejected because of their excessive nitrate content. Therefore, these plants would not be marketable in the European community. Regardless were found between either systems or sampling positions in the bed (Fig. 5). In contrast, Expt. 2 revealed significant differences $(P=0.004)$ between inlet and outlet in cNFT. The values decreased as the distance from the inlet increased. In general, the ascorbic acid concentration was higher in Expt. 1 than in Expt. 2 in both treatments, whereas an opposite tendency (i.e., lower values in Expt. 1 than in Expt. 2) was observed for nitrate concentration (Fig. 4). It has been reported that light and temperature are major environmental factors affecting ascorbic acid synthesis. Low light intensity and high temperature are associated with low ascorbic acid concentration (Isherwood and Mapson, 1962; Lee and Kader 2000; Toledo et al., 2002). Thus, it is probable that high temperatures and shading were the factors responsible for the lower ascorbic acid contents during Expt. 2. Nitrate concentrations, in contrast, were remarkably high during Expt. 2 (Fig. 4). Shinohara and Suzuki (1981) reported opposite tendencies for nitrate and ascorbic acid. Other literature also supports nitrate accumulation under low light intensity and high temperature conditions (Cantliffe, 1972a, b; Maynard et al., 1976; Mengel, 1979).

The dissolved oxygen of the nutrient solution at three different positions in the bed during Expt. 2 is presented in Fig. 6. In cNFT, the oxygen concentration was always lower at the outlet of the bed during growth. In addition, the difference between inlet and outlet tended to increase as plants grew and reached a maximum of $0.9 \mathrm{mg} \cdot \mathrm{L}^{-1}$ in the last measurement with plants in the bed (15 Aug. 2005). After harvest (16, 17, and 18 Aug.), the dissolved oxygen levels increased and there was no significant difference between positions in the bed, because there were no plants. Gislerød and Kempton (1983) found that an oxygen-depleted solution reoxygenated $(2.2-$ $\left.6.0 \mathrm{mg} \cdot \mathrm{L}^{-1}\right)$ after flowing down through a channel of $5 \mathrm{~m}$ without plants. In mNFT, dissolved oxygen tended to remain constant in all positions, and any differences observed were lower than those found in cNFT. Considering that the passing of the nutrient solution through emitters would favor gas exchange (as a result of the increase of the surface 


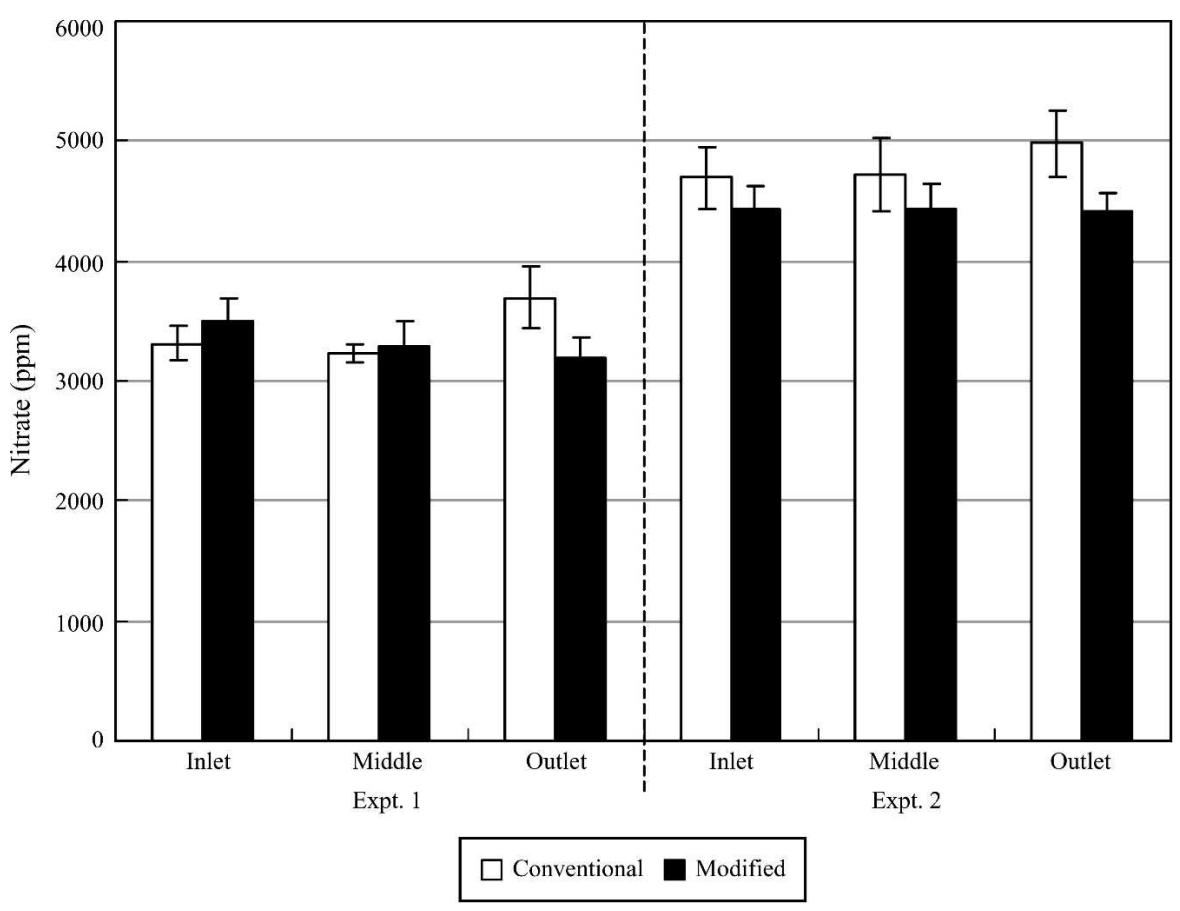

Fig. 4. Nitrate content of lettuce produced in a conventional (white bars) and a modified (hatched bars) nutrient film technique system during Expt. 1 (spring) and Expt. 2 (summer) according to the position in 18-m-long (59.1-ft) beds. Each value was averaged from five observations and shown with $\mathrm{SE} .1 \mathrm{ppm}=1 \mathrm{mg} \cdot \mathrm{L}^{-1}$.

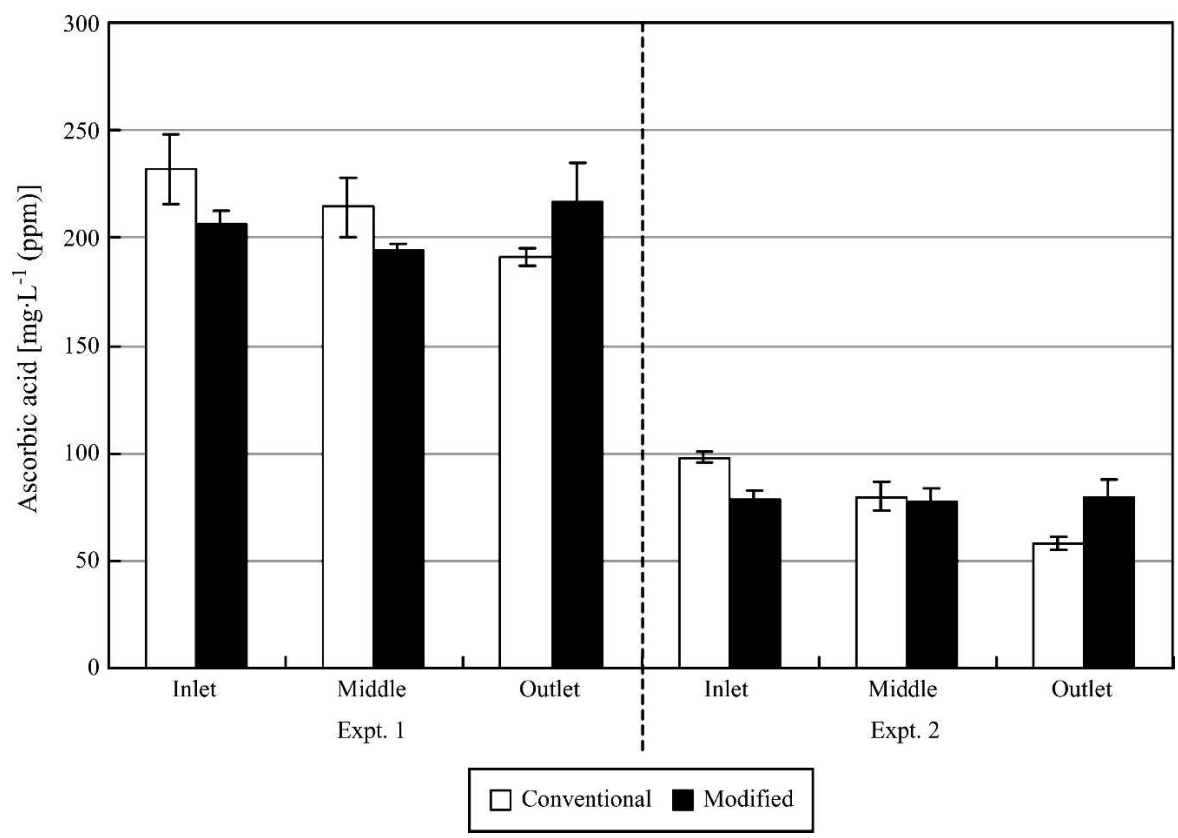

Fig. 5. Ascorbic acid content of lettuce produced in a conventional (white bars) and a modified (hatched bars) nutrient film technique system during Expt. 1 (spring) and Expt. 2 (summer) according to the position in $18-\mathrm{m}$-long $(59.1-\mathrm{ft})$ beds. Each value (shown with SE) is the average of three (Expt. 1) and four (Expt. 2) observations.

of solution exposed to air), it seems reasonable to assume that the oxygen concentration was always high and uniform along the bed in mNFT.
Oxygen depletion might be one of the factors responsible for the observed differences between treatments. Several researchers (Hurd,
1978; Jackson, 1980; Rudd-Jones and Winsor, 1978) have reported oxygen deficiency in cNFT systems.

The temperature at the outlet tended to be higher than at the inlet in cNFT ( 0.3 to $1.4{ }^{\circ} \mathrm{C}$, Fig. 7). Temperatures of cNFT and mNFT were close, and differences between the two ranged from 0.1 to $0.3{ }^{\circ} \mathrm{C}$. As in mNFT, the nutrient solution was delivered through a hose located at the side of the channel. Thus, the nutrient solution probably maintained lower temperatures. Although the average and the highest temperatures of the solution in the catchment tank were 28.3 and $38.9{ }^{\circ} \mathrm{C}$ (too high as root temperatures for optimal growth of lettuce) (Economakis and Said, 2002; He and Lee, 1998; He et al., 2001; Van Der Boon et al., 1990), the trend observed in $\mathrm{mNFT}$ may promise uniform plant growth, especially if the temperature of the nutrient solution could be controlled in the catchment tank.

In both experiments, the concentration of the nutrient solution did not differ between the sampling locations (data not shown). The results of this experiment contrast with those found by Winsor and Massey (1978), who reported significant concentration gradients of $\mathrm{N}$ and $\mathrm{K}$ along NFT beds in a tomato (Lycopersicum esculentum) experiment. The lower oxygen concentrations found at the outlet of cNFT might have weakened root activity to absorb nutrients, because oxygen contents less than $8 \mathrm{mg} \cdot \mathrm{L}^{-1}$ could considerably reduce the absorption of Ca, K, and P (Pepkowitz and Shive, 1943), and even quite small decreases in oxygen concentration can inhibit root extension and respiration (Chun and Takakura, 1994; Jackson et al., 1984). Thus, a lower uptake rate of these ions might have attenuated the difference in concentrations between inlet and outlet, and caused growth reduction in cNFT for plants farther from the inlet of nutrient solution.

The results of these current experiments demonstrate that plants of uniform size and quality parameters can be achieved in long cultural beds supplied with low-concentration solutions by using the proposed mNFT. We saw differences between systems in growth, oxygen concentration, and temperature. However, within this experimental design, we cannot 


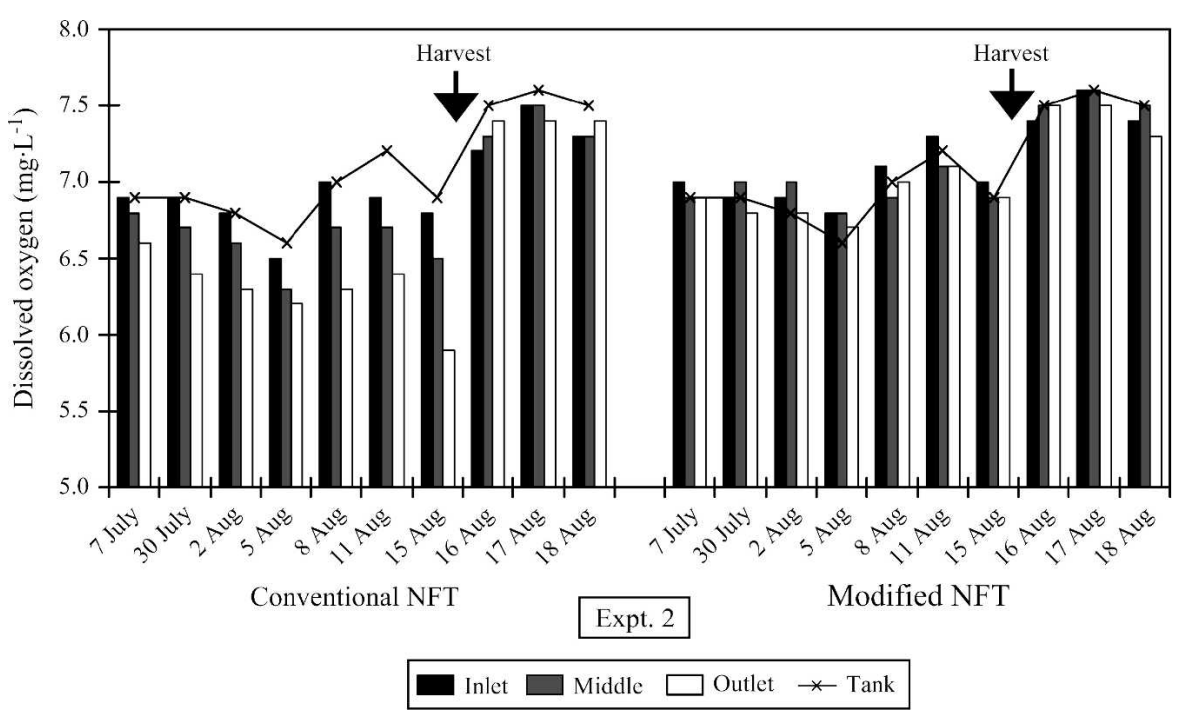

Fig. 6. Dissolved oxygen of the nutrient solution of two nutrient film technique (NFT) systems as affected by the position in 18 -m-long $(59.1 \mathrm{ft})$ beds during Expt. 2 (summer).

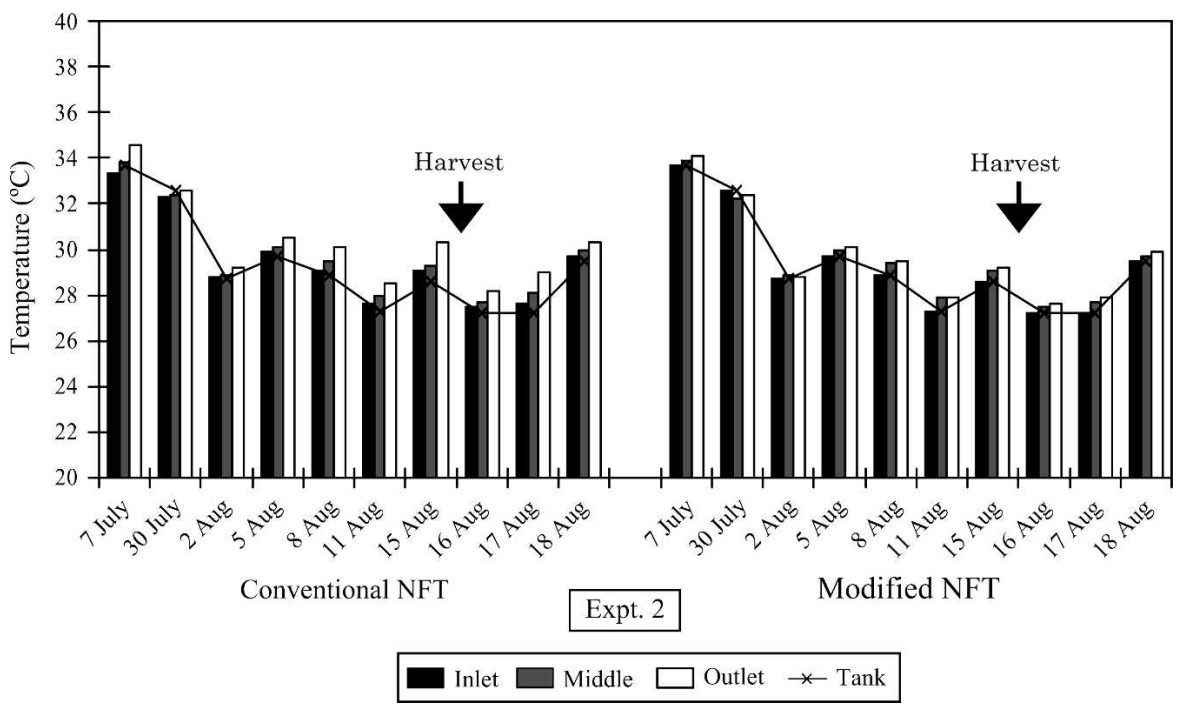

Fig. 7. Temperature (measured in degrees Celsius) of the nutrient solution of two nutrient film technique (NFT) systems as affected by the position in 18 -m-long (59.1-ft) beds during Expt. 2 (summer). ${ }^{\circ} \mathrm{F}=\left(1.8 \times{ }^{\circ} \mathrm{C}\right)+32$.

determine to what extent these differences are the result of the geometry of the two systems or the result of the differences in the flow rates used.

The design of this system ensures a relatively low variation in the characteristics of the nutrient solution applied along the channel, which leads to uniformity of the produce. A higher flow rate $\left(\approx 7.5 \mathrm{~L} \cdot \mathrm{min}^{-1}\right)$ appears to be better for this system; however, more experiments are necessary to confirm this hypothesis. Regarding the sideward slope, $3 \%$ proved to be suitable to allow a diagonal flow of the solution, while at the same time avoiding flooding which, would probably occur in
cNFT with a high flow rate. Moreover, an economic analysis is suggested to elucidate whether the observed technological advantage represents a real improvement in terms of net income for the farmer.

\section{Literature cited}

Andersen, L. and N.E. Nielsen. 1992. A new cultivation method for the production of vegetables with low content of nitrate. Sci. Hort. 49:167-171.

Cantliffe, D.J. 1972a. Nitrate accumulation in vegetable crops as affected by photoperiod and light duration. J. Amer. Soc. Hort. Sci. 97:414-418.
Cantliffe, D.J. 1972b. Nitrate accumulation in spinach grown at different temperatures. J. Amer. Soc. Hort. Sci. 97:674-676.

Chun, C. and T. Takakura. 1994. Rate of root respiration of lettuce under various dissolved oxygen concentrations. Environ. Control Biol. 32:125-135.

Cooper, A. 1979. The ABC of NFT. Grower Books, London.

Demšar, J., J. Osvald, and D. Vodnik. 2004. The effect of light-dependent application of nitrate on the growth of aeroponically grown lettuce (Lactuca sativa L.). J. Amer. Soc. Hort. Sci. 129:570575 .

Economakis, C.D. and M. Said. 2002. Effect of solution temperature on growth and shoot nitrate content of lettuce grown in solution culture. Acta Hort. 579:411-415.

Gislerød, H.R. and P. Adams. 1983. Diurnal variations in the oxygen content and acid requirement of recirculating nutrient solutions and in the uptake of water and potassium by cucumber and tomato plants. Sci. Hort. 21:311321.

Gislerød, H.R. and R.J. Kempton. 1983. The oxygen content of flowing nutrient solutions used for cucumber and tomato culture. Sci. Hort. 20:23-33.

Halfacre, R.G. and J.A. Barden. 1979. Horticulture. McGraw-Hill, New York.

He, J. and S.K. Lee. 1998. Growth and photosynthetic responses of three aeroponically grown lettuce cultivars (Lactuca sativa $\mathrm{L}$.) to different rootzone temperatures and growth irradiances under tropical aerial conditions. J. Hort. Sci. Biotechnol. 73:173-180.

He, J., S.K. Lee, and I.C. Dodd. 2001. Limitations to photosynthesis of lettuce grown under tropical conditions: Alleviation by root-zone cooling. J. Expt. Bot. 52:1323-1330.

Hurd, R.G. 1978. The root and its environment in the nutrient film technique of water culture. Acta Hort. 82:87-97.

Isherwood, F.A. and L.W. Mapson. 1962. Ascorbic acid metabolism in plants: Part II. Biosynthesis. Annu. Rev. Plant Physiol. 13:329-350.

Jackson, M.B. 1980. Aeration in the nutrient film technique of glasshouse crop production and the importance of oxygen, ethylene and carbon dioxide. Acta Hort. 98:61-78.

Jackson, M.B., P.S. Blackwell, J.R. Chrimes, and T.V. Sims. 1984. Poor aeration in NFT and a means for its improvement. J. Hort. Sci. 59:439-448. 
Jones, J.B., Jr. 1997. Hydroponics: A practical guide for the soilless grower. St. Lucie Press, Boca Raton, Fla.

Lee, S.K. and A.A. Kader. 2000. Preharvest and postharvest factors influencing vitamin $\mathrm{C}$ content of horticultural crops. Postharvest Biol. Technol. 20:207-220.

Maršić, N.K. and J. Osvald. 2002. Effects of different nitrogen levels on lettuce growth and nitrate accumulation in iceberg lettuce (Lactuca sativa var capitata L.) grown hydroponically under greenhouse conditions. Gartenbauwissenschaft 67:128-134.

Maruo, T., H. Hoshi, M. Hohjo, Y. Shinohara, and T. Ito. 2001. Quantitative nutrient management at low concentration condition in NFT spinach culture. Acta Hort. 548:133-140.

Maynard, D.N. and A.V. Barker. 1979. Regulation of nitrate accumulation in vegetables. Acta Hort. 93:153-162.

Maynard, D.N., A.V. Barker, P.L. Minotti, and N.H. Peck. 1976. Nitrate accumulation in vegetables. Adv. Agron. 28:71118.

Mengel, K. 1979. Influence of exogenous factors on the quality and chemical composition of vegetables. Acta Hort. 93:133-151.

Official Journal of the European Communities. 2002. Commission Regulation
(EC) no. 563/2002 of 2 Apr. 2002 amending regulation (EC) no. 466/2001 setting maximum levels for certain contaminants in foodstuffs. Office for Offic. Publ. of the European Communities. 3 Apr. 2002. <http://eur-lex.europa.eu/ LexUriServ/site/en/oj/2002/1_086/ 1_08620020403en00050006.pdf>.

Pardossi, A., F. Malorgio, and F. Tognoni. 1995. Control of mineral nutrition in melon plants grown with NFT. Acta Hort. 396:173-179.

Pepkowitz, L.P. and J.W. Shive. 1943. The importance of oxygen in the nutrient substrate for plants: Ion absorption. Soil Sci. 57:143-154.

Raviv, M. 1998. Assessment of various control strategies for recirculation of greenhouse effluents under semi-arid conditions. J. Hort. Sci. Biotechnol. 73(4):485-491.

Rudd-Jones, D. and G.W. Winsor. 1978. Environmental control in the root zone: Nutrient film culture. Acta Hort. 87:185-195.

Saavas, D. 2001. Nutritional management of Gerbera (Gerbera jamesonii) grown in a closed soilless culture system. Acta Hort. 554:175-182.

Saavas, D. 2002. Nutrient solution recycling, p. 299-343. In: D. Saavas and H. Passam (eds.). Hydroponic production of vegetables and ornamentals. Embryo Publications, Athens, Greece.
Schröder, F.-G. and J.H. Lieth. 2002. Irrigation control in hydroponics, p. 263-298, In: D. Saavas and H. Passam (eds.). Hydroponic production of vegetables and ornamentals. Embryo Publications, Athens, Greece.

Shinohara, Y. and Y. Suzuki. 1981. Effects of light and nutritional conditions on the ascorbic acid content of lettuce. J. Jpn. Soc. Hort. Sci. 50:239-246.

Thompson, H.C. and W.C. Kelly. 1957. Vegetable crops. McGraw-Hill, New York.

Toledo, M.E.A., Y. Ueda, Y. Imahori, and M. Ayaki. 2002. L-ascorbic acid metabolism in spinach (Spinaceia oleracea L.) during postharvest storage in light and dark. Postharvest Biol. Technol. 28: 47-57.

Van Der Boon, J.W., Steenhizen, and E.G. Steingrover. 1990. Growth and nitrate concentration of lettuce as affected by total nitrogen and chloride concentration, $\mathrm{NH}^{4+} / \mathrm{NO}^{3-}$ ratio and temperature of the recirculating nutrient solution. J. Hort. Sci. 65:309-321.

Winsor, G.W. and D.M. Massey. 1978. Some aspects of the nutrition of tomatoes grown in recirculating solution. Acta Hort. 82:121-132. 